Marquette University

e-Publications@Marquette

2020

What a Theological Appropriation of Cognitive Linguistics'

Blending Theory Brings to a Scientific Understanding of the Evolution of Religion

Robert Masson

Follow this and additional works at: https://epublications.marquette.edu/theo_fac

Part of the Religious Thought, Theology and Philosophy of Religion Commons 
Chapter 10

\title{
What a Theological Appropriation of Cognitive Linguistics' Blending Theory Brings to a Scientific Understanding of the Evolution of Religion
}

\author{
Robert L Masson
}

\section{Introduction}

What does a theological appropriation of cognitive linguistics' blending theory bring to a scientific understanding of the evolution of religion? The Cognitive Science of Religion has given a great deal of attention to the implications of its research for the evolution of religion. And a small but growing body of work has looked at the implications of the relatively new discipline of cognitive linguistics in the humanities, religious studies, and theology (Slingerland 2008; Masson 2014; Sanders 2016). But there has been little inquiry into the implications of theology for a scientific understanding of the evolution of religion. I will offer a few illustrative insights from a theological application of cognitive linguistics' blending theory to suggest that a "new" scientific study attentive to the interaction of cultural, biological, and psychological factors in the evolution of religion, also calls for robust research agendas responsive to advances in theology.

\section{A Brief Orientation to Blending Theory}

Neural mapping is the fundamental image in cognitive linguistics for thought, reasoning, conceptualization, and imagination. In the early stages of the 1980's and 1990's, cognitive linguists, particularly George Lakoff and a number of collaborators, sought to understand how meanings are mapped from "source domains," which are more familiar and concrete, to less familiar and more abstract "target domains" (Lakoff and Johnson 1980, 1999; Lakoff 1987; Lakoff and Turner 1989). This research has been extremely effective at clarifying a range of conceptual and grammatical issues that had previously resisted satisfactory theoretical explanation, such as how prepositions work across languages or how categorizations work. According to this research, reasoning and concepts are not literal, abstract, and disembodied. Rather our conceptual systems and inferences arise from, use, and are crucially shaped by the perceptual and motor systems of our bodies and the neural systems of our brains. Metaphorical mappings are not secondary and illustrative. Reasoning is guided by metaphorical mappings derived from our embodiment. This metaphorical mapping is a fundamental and pervasive feature of human thought and language. Physical motion, for example, provides the underlying conceptual mapping that guides much of our thinking about time, change, and actions. We conceptualize time as "flying," "ahead" of us, "behind" us, "stopping," or "going on" forever. We "move" through time. Time "passes" us by.

Lakoff and his followers conclude from their research that the imaginative aspects of cognitionmetonymy, metaphor, framing, image schemas, and mental images - are crucial and primary, not derivative and secondary. From this perspective, objectivity, precision, and stability in cognition are possible, but literal meaning is not the default position or foundation. It is just the opposite. Words call for meaning rather than capture it. Language is an underspecified tip of a giant iceberg of underlying and mostly unconscious cognitive processes of categorization and metaphorical mapping.

Recent research in cognitive linguistics (Fauconnier and Turner 2002; 2008)provides evidence for the claim that conceptualization and inference are much more complex than the earlier metaphorical mapping model suggested. Conceptualization and inference are hardly ever the result of a single mapping between a source domain and a target domain. Rather conceptualization and reasoning typically involve the integration of many mental spaces and mappings within more elaborate conceptual networks. Blending provides a process through which very complex networks of meaning can be compressed into human 
sized concepts that we can handle and with which we can make manageable inferences. Then we can decompress these human sized compressions when more fine-tuned explanation and reasoning are required. Such blends enable the compression of complex networks of meaning.

Blending theory proposes an explanation of the processes involved in these complex conceptual integrations. Fauconnier and Turner describe the range of conceptual integration in terms of four prototypical blends that they name simplex, mirror, single-scope, and double-scope. The first corresponds to what we conventionally describe as literal. A relatively simple example is the blend PAUL'S DAUGHTER. The blend combines inputs from one space or frame (kinship roles, like father, mother, daughter, son, etc.) with another space (a set of individuals, like Sally, Molly, and Peter). The blending of the conceptual spaces in "Paul's daughter," is so automatic and unconscious that we do not even notice it.

The second network is called a mirror blend because the two inputs mirror each other. Fauconnier and Turner (2002, 59-60) imagine a contemporary philosopher who tells us,

I claim that reason is a self-developing capacity. Kant disagrees with me on this point. He says it's innate, but I answer that's begging the question, to which he counters in The Critique of Pure Reason, that only innate ideas have power. But I say to that, what about neuronal group selection?

One could take this as a straightforward logical argument. One might not even notice the complicated cross-space mapping that prompts us to conceptualize this situation as a dispute between two people in the same place and time. Kant and the professor lived centuries apart, in different countries, and speak different languages. Such a debate never took place and never could. But we have no problem entertaining such a possibility in the course of a rigorous philosophical argument. Thomas Aquinas's Summa Theologiae is largely framed by such debates with authorities from the past. "Running the blend," compresses time and space; cause and effect; change; and intentionality. In the Summa's extended blend, Aristotle, Augustine, and other ancients are put into dialogue with each other and with Aquinas's "contemporary" resolution.

Single-scope blends differ from mirror networks in that the structure derives from one of the input spaces. One of the inputs gives the overall organizational structure of the network and is the primary source of inferences. These are strongly asymmetrical. The framing input is a source of inferences and compressions. Much of what we commonly call metaphors, analogies, and models are variations of single-scope blends. Single-scope blends highlight certain properties common to the two input spaces, such as, similarities, parallels, or proportions, even though the two input spaces are themselves quite different. Among the many blends Fauconnier and Turner examine is a scenario in which competition between two CEOs is conceptualized as a boxing match in which one CEO delivers blows to the other CEO and ultimately knocks the other out of business (2002, 126-131).

The most complex and distinctively human blends are double-scope ones. For cognitive linguists "double-scope" means that they are bidirectional blends that create new emergent meanings and new possibilities for inference. In double-scope blends there are two inputs, both of which contribute to the blend's meaning. The two inputs commonly clash. The differences between the spaces, particularly if they clash, prompt new, often unanticipated, meanings. The key thing to note about double-scope blends is their capacity to call for a new understanding. For example, the mathematics we use today has evolved through the centuries and enables achievements not possible with the number systems available in earlier ages. Complex numbers, for example, are in effect a double-scope network with inputs from twodimensional space and from real and imaginary numbers $(2002,25 ; 134 ; 270-274)$. Structure is projected 
from both inputs. From two-dimensional space, angles, rotations and coordinates are projected. From numbers, multiplication, addition, and square roots are projected. The blend that emerges is something new and unique: numbers with angles and multiplication involving rotation. With this new and emergent dimension in mathematics, new ways of calculation and new understanding becomes available. This dramatically reconfigured what mathematicians were able to conceptualize and infer. It took roughly three centuries for mathematicians to accept these developments. The natural sciences provide other dramatic examples of the emergence of new understanding, such as the Newtonian synthesis that the LAWS OF Heaven Are The Same As The Laws Of EARTH, the Thompson/Joule discovery that Heat Is Motion, or Einstein's E=mc ${ }^{2}$ (Gerhart and Russell 2001, 23-27; 53-54). In such cases as complex numbers and these revolutionary blends in the natural sciences, the emergence of new meaning creates conceptual space for ways of understanding and of making inferences that was not previously available.

This potential for the emergence of entirely new meanings and inferential possibilities is what makes double-scope mapping so distinctive. Fauconnier and Turner postulate that this capacity explains the development of language in human evolution and explains the cognitive process at the heart of religion, art, science, and technology. This double-scope blending gives human understanding an extraordinary open-ended equipotentiality to create and manipulate new conceptual networks. Languages, cultures, the sciences, and religions have been built up over generations through the cobbling and sculpting of such integration networks. These networks of meaning are never built entirely from scratch or on the fly. Nor are they ever entirely pre-existing conventional structures. They are always a mix of both. Cultures build networks over long periods of time which are transmitted over generations. Each generation builds on previous integrations that have become conventional and each adds new novel mappings and compressions. Fauconnier and Turner argue that "for any situation, real or imaginary, there is always a way to use language to express thoughts about that situation" $(2002,179)$.

\section{Conflicting Readings of Blending Theory's Implications for the Evolution of Religion}

My own experiment with a theological appropriation of the research in cognitive linguistics was preceded by Edward Slingerland's much more ambitious, broad-ranging, and provocative analysis in What Science Offers the Humanities. That book's central objective is to argue for the vertical integration of the sciences and humanities. For Slingerland, vertical integration means that "lower" levels of explanation are in significant ways more basic than "higher" levels (17). His goal is to articulate an understanding of the vertical integration of the sciences and humanities as an alternative to the status quo which he sees beset by the excesses of objectivist intellectual imperialism, on the one hand, and postmodern relativism, on the other hand. As part of this larger agenda, Slingerland makes an avowedly atheistic case "that evolution is the best explanation for how people and everything else in the universe got here" and that consequently there is no scientific justification for believing in supernatural beings or souls (286). He contends that the inevitable conclusion of science "means that the self as we ordinarily understand it - as a disembodied something, soul or spirit or mind, caused by nothing other than itself - is nothing more than an illusion created by the workings of our embodied brain" (257).

Slingerland's appropriation of blending theory provides an interesting contrast to my proposal. We both draw heavily on Giles Fauconnier and Mark Turner's research, particularly their thesis that blending theory provides a compelling explanation of the emergence of the cognitive capacity from which language evolved and which accounts for the cognitive processes that made possible a "cultural big bang" in art, religion, and technology 30,000 to 60,000 years ago. Likewise, we both argue that the emergence of these cognitive capacities is crucial for understanding advances in the sciences and humanities today. 
Moreover, as a Sinologist, Slingerland draws his paradigmatic illustrations from his research in early Chinese Confucian thought, while I draw my illustrations from the Christian tradition. Finally, we both aim for more significant collaboration between the sciences and the humanities and draw on Charles Taylor's conception of a scientific realism that includes human-level accounts of reality. At that point we diverge. Slingerland argues that with blending theory evolutionary science can explain how humanity's open-ended consciousness emerges from a chain of causality that is entirely natural and physical. A vertical integration of the sciences and the lack of a viable alternative theory (278) lead him to the thesis that

as products of a blind process of replication and selection, human beings as a whole - body and mind - differ only in degree of complexity from robots or machines: we, like everything in the world, are causally determined, purely physical systems (250).

I agree that blending theory and cognitive science help explain the emergence of the underlying biological mechanisms and cognitive processes entailed in human evolution. But blending theory also puts in sharp relief the emergence of dramatic and revelatory shifts in human conceptualization and inference that are ignored in Slingerland's evolutionary construal. I am not talking here about the acquisition of new data or the extension of existing concepts but rather have in mind shifts in thinking that yield brand new ways of understanding, such as the theory of evolution itself. The "discovery" of evolution and natural selection are not additions of new factual information or even extensions of what counts as fact. Evolution and natural selection are brand new ways of thinking about the facts and of construing what counts as fact. While evolutionary theory provides a framework for explaining the underlying capacity for the emergence of new understandings of this sort, it does not and cannot provide an adequate and complete explanation of the new understandings themselves. Explaining the origins of new understandings of this sort, whether of evolutionary understanding, or more broadly of scientific thinking itself or of religious thinking, is different from explaining the evolutionary origins of the cognitive capacities for these humanlevel activities. Explaining how these capacities have "evolved" historically, culturally, and conceptually into fundamentally diverse ways of thinking and engaging "reality" requires entertaining further humanlevel ways of understanding (e.g., historical, philosophical, literary, and theological) in addition to the natural sciences' third person empirical accounting. Slingerland makes this case to an extent in arguing that certain novel, and even counterintuitive, blends such as the mathematical concept of zero or the idea of weight as an extensive property "provide the cultures that possess them with new tools for reasoning about and even looking at the world" (207). But Slingerland does not entertain the possibility of emerging equally legitimate counterintuitive religious blends that provide novel ways for understanding and explanting reality because, in his judgment, the natural sciences answer empirical questions more satisfactorily and because Darwinism has rendered meaningless the big "why" questions that now seem to be the sole concern of religion (231-232).

Slingerland anticipates this line of objection. He admits that he struggles with the implications of Darwinism's "universal acid."

I don't believe in supernatural beings or souls. And yet, at some level, I cannot help but feel that, for instance, I was "meant" to meet my wife.... I don't believe in an afterlife or a nonmaterial soul, and yet, if you press me, I would have to admit to a sneaking feeling that my favorite grandmother is somehow watching me....

We will apparently always see meaning in our actions - populating our world with "angry" seas, "welcoming" harbors - and other human beings as unique agents worthy of respect and dignity, and distinct from objects in some way that is hard to explain in the absence of soul-talk, but nonetheless very real for us. We will continue 
to perceive our work, families, and lives as being "meaningful" at some inchoate level, and to be strongly motivated to make the appropriate changes whenever we begin to lose this sense. (286-87)

Despite this inevitability, Slingerland insists that we must admit that from the perspective of science this feeling is an illusion with which, for better or worse, we must live. "We are apparently designed to be irresistibly vulnerable to this illusion" (287). He acknowledges that "this is where, in fact, we see the limits of a thoroughly 'scientific' approach to human culture and need to finesse a bit our understanding of what counts as a "fact for beings like us" (287).

But finessing the account for Slingerland means "living with a kind of dual consciousness, cultivating the ability to view human beings simultaneously under two descriptions: as physical systems and as people" (293). But unlike Taylor, Slingerland is convinced that human-level descriptions and dual consciousness, however inevitable and unavoidable, are nevertheless based on misapprehensions. For Slingerland, Darwinism is a mortal threat to conventional religious beliefs and conceptions of the self: "once we have begun down the physicalist path we cannot go back to the old certainties" (291). Because fundamentalists also recognize this, Slingerland believes they "are in fact a bit ahead of the curve" (255). Consequently, while Slingerland agrees with Taylor that human-level concepts necessarily have a hold on us and can serve valuable purposes, he is not willing to follow Taylor and say that human-level reality "is just as real as anything studied by the natural sciences" (290). Rather "the short response to Taylor is that, at least for anyone even casually familiar with the current state of the art in the cognitive sciences, human reality is simply not as real as physical reality" (290). "Evolution is such a relatively new idea, and its message is so fundamentally alien to us, that its real implications for our picture of human reality have yet to fully sink in" (291). Despite how counterintuitive the evolutionary picture of reality is, it will and must, for Slingerland, prevail over the human-level dualist picture because evolution has built us "in such a way that we want to deal with and picture the world as it 'really' is, no matter how unpleasant" (291).

Let me explain why I think an engagement of cognitive linguistics' blending theory and theology suggests that Slingerland's picture of the "world as it really is" is incomplete and does not overcome the dualist picture of body and spirit but is rather itself a captive of that picture. My different explanation about blending theory's relevance to the multiple human-level ways of picturing reality as it actually is, while admittedly far short of addressing all Slingerland's broad ranging arguments, nevertheless, has implications for how to construe a multi-disciplinary investigation of the evolution of religion.

\section{Tectonic Blends}

Slingerland sees the "ratcheted" innovations of conceptual blending as providing a framework for explaining how human thought can evolve from the embodied interaction with the physical world. $\mathrm{He}$ takes this framework to cohere seamlessly with the physicalists conception of evolution that he believes is warranted by the research in cognitive and evolutionary science and so explains the origins of religion. This inference that evolutionary theory is all that is needed to explain the origin of religion is the crucial point of disagreement between our appropriations of blending theory. I think some ratcheted innovations are more tectonic than Slingerland's account appears to acknowledge. While Slingerland clearly emphasizes that blending involves a watershed development in the cognitive capacities of human beings, it is not clear, as I mentioned previously, that his position fully accounts for the degree to which some blends generate entirely new ways of explaining and understanding that are different from physicalists explanations but nevertheless are not necessarily opposed to realist understandings of our embodied 
human nature and physical world - and that are not necessarily dualist in the ways that Slingerland conceptualizes them. Moreover, his position does not clearly account for how the substance and details of blends are entailed in the generation of these new ways of understanding and explaining. No doubt Slingerland would see this reaction as indicative of a typically humanist slide into a dualism of spirit and matter that lacks the courage to face the implications of empirical evidence. But for the sake of argument, consider a few blends which I propose as evidence for a different way of picturing the situation.

\section{Jesus is the Messiah}

In the Christian faith, JESUS IS THE MESSIAH is a prototypical example of the kind of "tectonic" doublescope blend that gives evidence for a different way of viewing things. The blend is at the heart of Christian understanding. Despite appearances, the proclamation by his earliest disciples that Jesus is the Messiah could not have been literal. If Jesus was the Messiah, then he was no ordinary carpenter's son, and he was much more than an itinerant preacher who was deserted by his followers and crucified. Moreover, "Messiah" at the time did not name a single category. It was associated with a multiplicity of expectations, some of which were mutually exclusive, including an otherworldly figure who descends from the heavens and a royal and "this worldly" descendent of David. Given these conventional meanings of Messiah, applying the term to Jesus after his crucifixion would not have made literal sense to the first disciples' addressees. But it is also clear that when his disciples regrouped and proclaimed Jesus the Messiah, they were not speaking figuratively. This was not a mirror or single-scope metaphorical blend. His followers were not saying that Jesus is "like" a Messiah or proposing that people should think of him "as if" he was a Messiah. The disciples were not merely mapping some attributes of the Messiah onto Jesus, nor simply mapping in the other direction attributes of Jesus onto the Messiah. Nor were the disciples analogically claiming that Jesus was partly similar and partly dissimilar to the expected Messiah. Instead, they clearly intended their claim to be taken quite "literally": Jesus is the Messiah. And the claim can be taken in this way "literally," or at least "properly," to use a less misleading term, only if the affirmation is understood as a double-scope blend that maps in both directions at once and that calls for a tectonic alteration of the conventional meaning of Messiah and the network of meanings associated with the concept.

The disciple's blend, therefore, was extraordinary and uncalled for. In the blend, Jesus's life becomes the new prototype for understanding the Messianic expectation, while the Messianic expectation discloses Jesus' true identity. Further, the blend calls for a revision of the original inputs. The disclosure of a new frame of understanding in which Jesus is the Messiah radically extends the conventional meaning of the category of Messiah and establishes the crucified carpenter's son from Nazareth as prototype against 


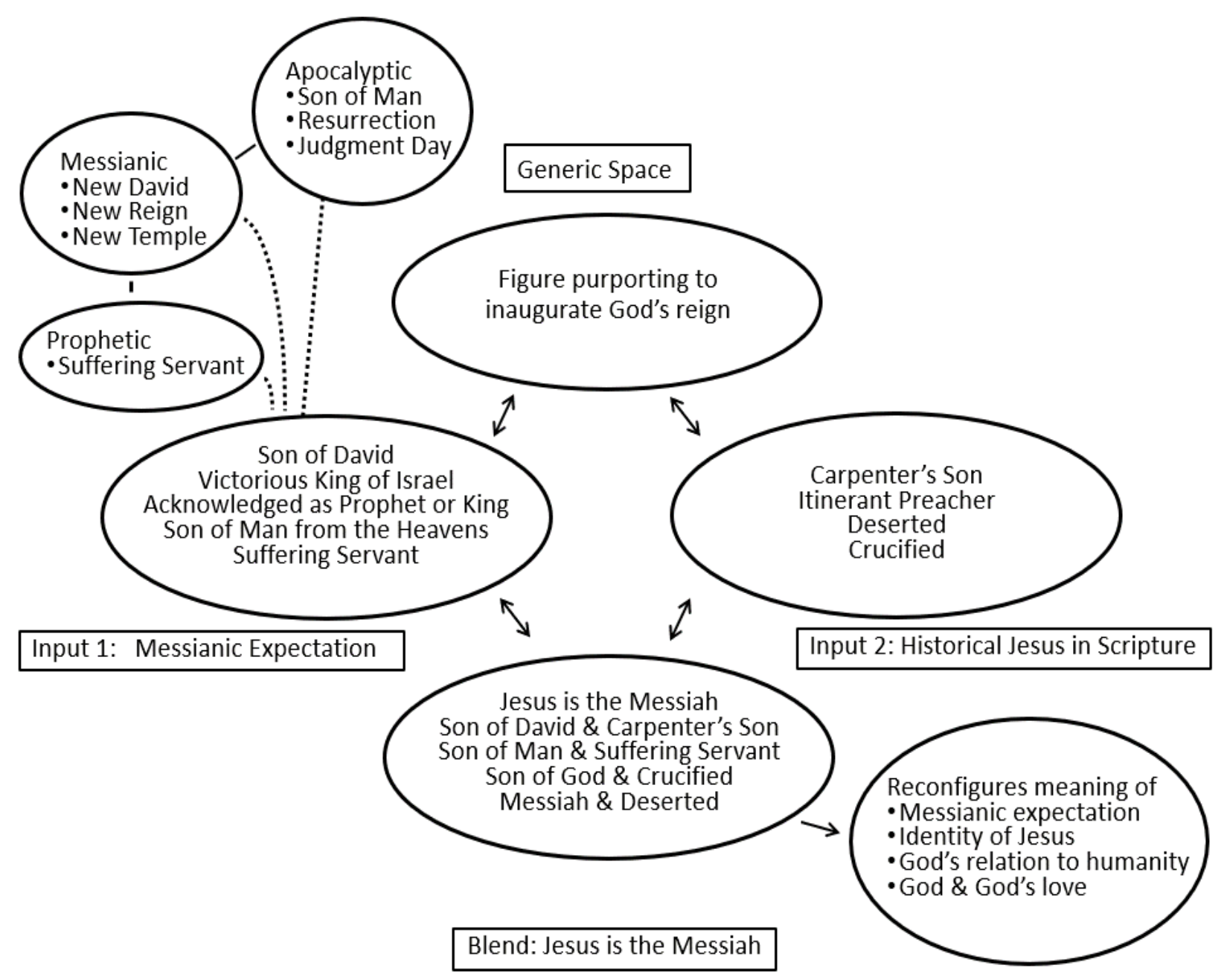

Figure 1 JESUS IS THE MESSIAH blend. The blend maps in both directions between messianic expectations and the historical Jesus mediated by Scripture thus prompting for a tectonic alteration of the conventional meanings of Messiah and of the network of meanings associated with the concept and with Jesus.

which all other conceptions are measured. Moreover, the advent of God's kingdom in this unanticipated Messianic savior reveals a new understanding of God and of God's relation to humanity. So the blend prompts for a tectonically altered understanding of Jesus, Messiah, God, humanity, and the whole network of meanings and frames associated with these terms and entailed in understanding the relationship between the divine and human generally and understanding the case of Jesus specifically. The blend demands an understanding that otherwise would be unavailable, and it makes possible new inferences that otherwise could not have been envisioned. Thus, the details and substance of the blend's inputs are constitutive of this new way of understanding. Although "Jesus is the Messiah" is not literal in the conventional sense, the Messianic claim in the blend makes an assertion that is proper, logically warranted, and factually the case - hence the need to distinguish its tectonic logic from conventionally conceived literal, metaphorical, and analogical logics. 
Jesus's disciples were forcing an equivalence between him and the Messiah that would not have made sense to contemporary Palestinian Jews unless they were also ready and open to a significantly tectonic stretching of their language and understanding, so this shift emphasizes that the blend was calling for a new understanding. In this way, tectonic blends are a bit like quirky humor. We say that a person has to "get" a joke to think it funny. One can entirely "miss the joke," that is to say, the person can miss that a joke is even being made. But when a person does not laugh at a joke, it could mean instead that the person understood the joke but didn't find it funny. From the perspective of blending theory, we can distinguish at least six different possible receptions of a double-scope blend for a person:

1 Able to run the blend.

2 Able to run the blend and accepts it.

3 Able to run the blend and rejects it.

4 Mistakes the double-scope blend for a literal claim.

5 Mistakes the double-scope blend for an entirely metaphorical and figurative claim.

6 Mistakes the double-scope blend for a simple analogy.

There are contemporary and historical instances of each of these responses to the disciple's prompt (call for new understanding).

It is important to keep in mind two final points. First, the creation of conceptual blends and their reception are pervasive and largely unconscious cognitive processes. That was almost certainly the case with the JESUS IS THE MESSIAH blend. I expect that while the blend was unexpected and world changing for his followers, it might have seemed obvious and natural to them, once proposed, given their experience of Jesus, his fate on the cross, reports of his appearances, and how they had been primed by Messianic expectations and images. One can surmise that for those who got the prompt, like getting a joke, the processing was quick, reflexive, unconscious, and natural. The same is likely true for those who rejected the prompt and those who missed it altogether.

Second, prompting for new meaning in no way guarantees that the prompt will be grasped, understood, or accepted. Recognizing that "Jesus is the Messiah" is a double-scope blend does not settle whether it is a helpful way of looking at things or whether it is true. The decisive point I mean to illustrate, however, is that recognizing that it is a double scope-blend is absolutely necessary for understanding how the Messianic claim purports to be true and helpful. One can see in the gospels a multitude of narrative devices aimed to prime the hearer for the revelatory conclusion and tectonic prompt. That is the narrative function of the stories about uncomprehending disciples, Jesus's abandonment on the cross, a doubting Thomas, and post-resurrection appearances in a locked room and at Emmaus. Such narrative elements signal disruptions and reconfigurations in the conventional Palestinian world of meanings. In this light, a fundamentalist appeal to historical evidence to justify the claim that Jesus is the Messiah suffers from the same shortcoming as the arguments of skeptical historians who contend that proof is lacking. Neither is ahead of the curve. Both miss the tectonic logic of the blend. Both miss that a quite different way of understanding is proposed. This is not to say that it would be impossible for a fundamentalist or a skeptical historian to comprehend that the Messianic attribution is a tectonic double-scope blend. But once recognized, this characterization demands different sorts of counterarguments and evidence than entertained by fundamentalists and skeptics. Nor does a double-scope interpretation of the Messianic claim fit the assumption in much of the research in the Cognitive Science of Religion that theological and doctrinal beliefs evolve from more literal and naive conceptions (See Masson 2014, 165-188). Rather, seeds for the emergence of a new religion - that it to say, the emergence of a self-consciously new way of understanding God and of explaining God's relationship to humanity-were inherent from the beginning 
in the tectonic double-scope logic of the disciples' assertion that Jesus is the Messiah. This was the case, even though the historical evidence does not prove that anything of the sort was consciously envisioned by Jesus or his first disciples.

\section{God is simple}

St. Thomas's conception of God offers even subtler illustrations of tectonic theological blends. Let's look at two which I describe in Without Metaphor, No Saving God. The first is Aquinas's affirmation that GOD IS SIMPLE. Aquinas asks whether God can be located semantically the way other realities can? Is God a body? Is God composed of matter and form or of substance and accidents? Is there any way in which God is composite or enters into compositeness with other things? As David Burrell has shown, "In one article after another, Aquinas monitors each possible way to get hold of something: locating an object in space and time or saying anything about it" $(1979,18-19)$. The upshot is that for Aquinas "God escapes our grasp on every count." In the case of every other reality (whether physical, mental, real, or imaginary), one can locate the thing and speak about it as a composite of matter and form, accidents and substance, potency and act, genus and species, or form and esse. God is beyond this sort of description. Thus, Aquinas articulates a double-scope blend to call for an understanding that reaches beyond the available categories.

The blend does not describe a feature or characteristic of God that we can directly grasp or comprehend. Even though the term "simplicity" is a substantive and thus sounds like a quality or description of God, Aquinas uses the term as shorthand for denying that any substantives, at least as we know them, can apply to God except in this indirect way. Both input spaces presume the metaphor PREDICATION Is A FORM OF CONTAINMENT but the effect of predicating "simplicity" in the blend is to use a substantive in a way that denies that substantives apply to God. The blend uses the metaphor of containment to elicit the counterintuitive notion of an uncontained reality.

So the "simplicity" that Aquinas attributes to God, although related to "simplicity" as it is known in this world, is at the same time nothing like "simplicity" as we know it and experience it. To grasp the meaning and assess the truth of the claim that God is simple, one has to understand the new logic and way of conceptualizing things inherent in the new meanings for which "simplicity" in the blend calls for. Moreover, this blend, like the JESUS IS THE MESSIAH blend, also calls for a change of meanings in the broader frame (the two input spaces). Since the blend entails that it is entirely proper to affirm that God is simple, God becomes the prototype of simplicity. Aquinas holds that simplicity and all other perfections are attributed to creatures only imperfectly.

\section{God's essence is "to be"}

A similar logic is entailed in Aquinas's affirmation that in God essence and esse are identical. Aquinas's blend subverts the metaphor that CATEGORIES ARE CONTAINERS to call for a fundamentally different way of understanding God. The act of assertion (affirming that something exists) is logically different from predication (affirming that something has this or that quality). When we say that something exists, we are not describing any particular feature of the reality. In affirming that God's essence is "to be," Aquinas is not giving a description of God in the ordinary sense of things, because "to be" is not a thing or predicate in the ordinary sense. Saying that God's nature is "to be" does not give a definition or grasp of God's nature. What "to be" signifies cannot be grasped directly in a concept. Nevertheless, as David Burrell has pointed out, the grammatical analogy between asserting things "to be" and affirming predicates of things, enables Aquinas to stretch predication and to generate a "substantive" for God in a way that denies substantives apply to God. (34-50). In employing this structural analogy, Aquinas's blend extends 
language. The blend forces an equivalence between the logic of asserting and the logic of predicating - to display and speak of what is beyond language's grasp.

Both of Aquinas's blends prompt for a tectonic change in our fields of meanings, opening radically new ways of conceptualizing God and making inferences about God.

Aquinas's blends do not reify God. They do not conceptualize God as a disembodied something that we can reach through normal modes of predication. Indeed, the point of Aquinas's conceptions of God's simplicity and essence is to articulate blends that subvert the limitations of language that otherwise leave us with dualist notions of embodied and disembodied somethings, the material and immaterial, or the physical and spiritual. The point of Aquinas's blends is to call for different "tectonic" ways of understanding and explaining these distinctions in the tradition that he inherits and passes on. 

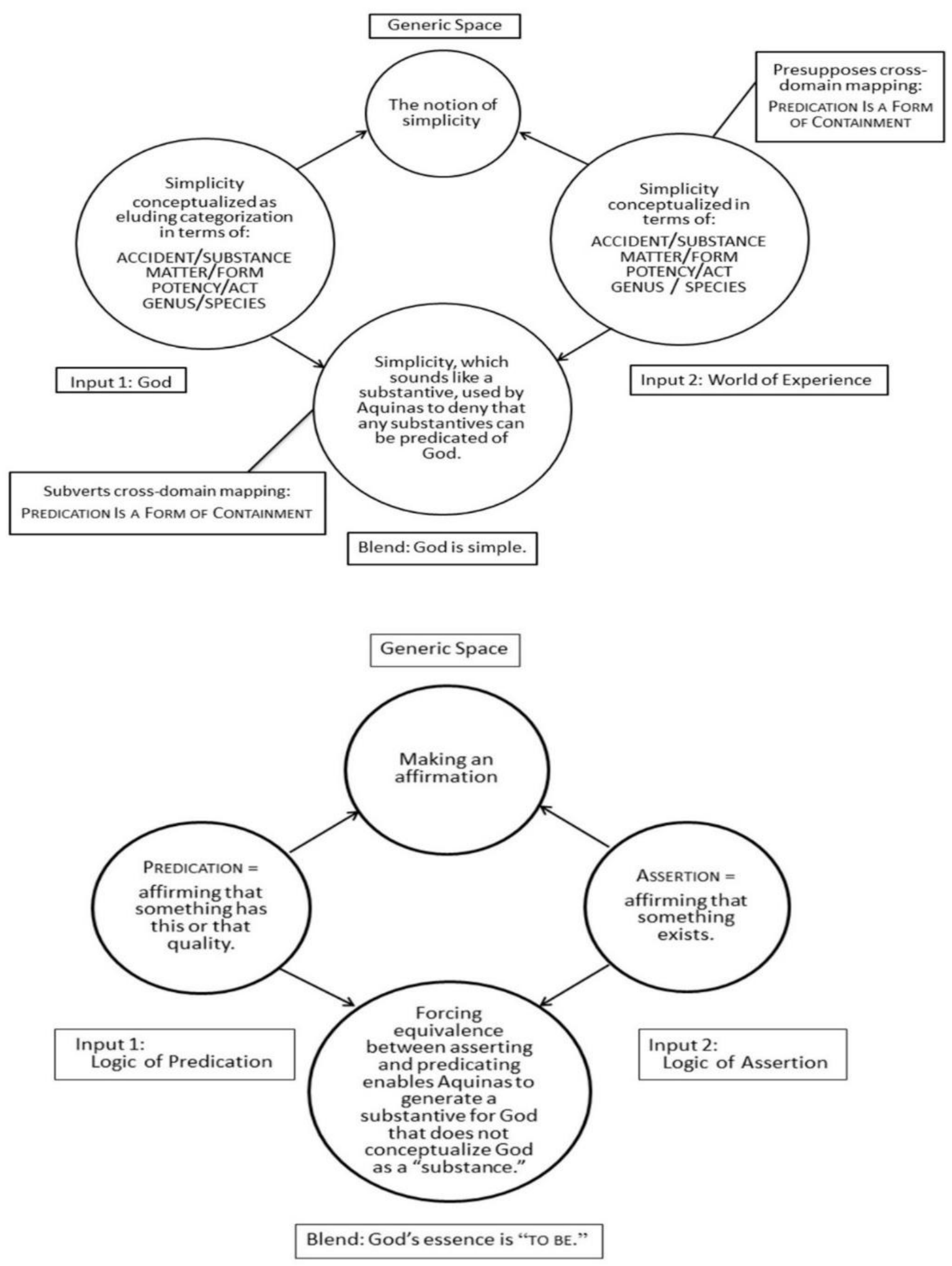

Figure 2. Aquinas's blends. (a) Aquinas's God is simple blend subverts the cross-domain mapping that presupposes that predication is a form of containment by generating a predication 
(i.e., a meaning and affirmation of simplicity) that denies that God can adequately be grasped by any predication and (b) Likewise, his God's essence is "to be" blend forces an equivalence between asserting that "God is" and predicating that God's essence is "to be," enabling him to call for a way of thinking about God that subverts the idea that God can be conceptualized or affirmed as a "substance

Of course, Aquinas himself and his followers would say a different "analogical" rather than "tectonic" way of understanding. I use the term "tectonic" to draw attention to the double-scope tectonic character of Aquinas's logic that blending theory brings to light.

Some readers might react to this explanation with the response of skeptical analytical philosophers that Aquinas makes a naive category error here: his metaphysics is language gone on a holiday. While such skeptical readers would be inclined to suspect that Aquinas has been fooled by language and a metaphysical muddle, I argue that that Aquinas's novel integration of neo-Platonic and Aristotelean metaphysics and his attentiveness to grammar enables him to articulate a tectonic double-scope blend that calls for a brand-new way of understanding God and of conceptualizing God's relation to humanity. Aquinas is taking advantage of the way our minds are structured and stretching grammar to conceive God in a way that is consistent with the Christian tradition's complex networks of meaning. That web of multiscope blends developed over hundreds of generations, and it is embodied in the community's complicated and often fractious multiplicity of narratives, worship practices, doctrines, theologies and both personal and shared experiences of wonder, suffering, and grace. Making a judgement about whether to accept or reject novel double-scope blends such as these requires that one has taken in the blends' distinctive logics, motivations, and warrants in their various historical and cultural contexts.

\section{Implications for the evolution of religion}

In Slingerland's picture the only substantive factors that matter in the evolution of religion are empirical and they are fully explained by Darwinism. Slingerland does not seriously probe the conceptual mapping of notions such as God, spirit, or soul. Rather, his picture equates such concepts with naive, vague, and static notions of "disembodied somethings." Moreover, according to Slingerland the idea "that the essence of religion is to explain the big "why' questions is relatively recent," and in any case is rendered meaningless by Darwinism because among other things "the big 'why' questions are not amenable to empirical testing" (231-232). He takes for granted the popular picture that "religion used to explain a much wider range of phenomena, and it continues to do so in cultures less penetrated by modern science" (231). But for Slingerland "religion seems to us now to be concerned solely with ultimate concerns because this is its last stronghold, to which it has systematically been forced to retreat" (231). In this picture, undergirded by the literature in the Cognitive Science of Religion, the significant advantages of projecting agency into the world at large has so influenced our evolution that we cannot help but believe that we "inhabit a universe full of other soul-bearing human beings, as well as animals endowed with various degrees of consciousness, anthropomorphic gods, angry seas, and threatening storms" (26). So, we have evolved as human with a dual consciousness that makes us incapable at one level of fully embracing the implications of science and evolutionary theory but at another level compels us to seek the truth about reality which is at odds with our human-level experience.

If fundamental conceptions in Christian thinking, such as the biblical claim that Jesus is the Messiah or Aquinas's conception of God, are appropriately described as tectonic double-scope blends, a different picture is taken. These blends:

- Call for significant changes in a larger network of meanings. 
- Have roots in prior, conventional inputs but genuinely transcend them.

- Result in the creation of new ways of understanding that otherwise would be inconceivable.

- Create the possibility for inferences that would otherwise be inconceivable.

- Make assertions that are semantically proper, logically warranted, and factually the case, but that cannot be read straightforwardly as either literal or metaphorical.

- Require thick contextual interpretation because the new meanings and inferential possibilities are a function of the blend's unique construction.

- Call for meanings (e.g. Messiah, God's simplicity, God's being) that despite appearances do not necessarily conflict with a scientific understanding of the world as physicalist interpretations like Slingerland's assume.

In the picture I am suggesting, the origins of Christianity are rooted in a highly differentiated call for a brand-new way of understanding God and of explaining God's relation to everything else. Christianity's inception was not just a matter of new information or beliefs. The two-thousand-year history of responses to that prompt is the community's running of the blend. Running the blend entailed working out a cascading network of multi-scope mappings, including the identification of Jesus's humanity with God and the tectonically different way of understanding God the Aquinas's blends calls for.

A second aspect of the picture I am suggesting is that the illustrations we have examined, in prompting for new ways of understanding the reality of God and of God's relation to humanity, correspond to the big "why" questions of "ultimate concern." Religions once may have sought in part to explain things that are now better understood by the natural and social sciences, but that does not prove that the big "why" questions for which the Messianic claim and Aquinas's blends prompt were peripheral until recently. To the contrary, Michael Buckley has demonstrated that what in fact is "recent" is the conception of God as the specific kind of "causal agent" (the first in the chain of empirical causes) that developed in $17^{\text {th }}$ century and $18^{\text {th }}$-century apologetics $(1987,2002)$. Aquinas's tectonic blend entails entirely different notions of causality and agency (Burrell, 1979; McCabe 1987). Countless contemporary theologians follow Aquinas's prompt and insists that the human and divine, or matter and spirit, though distinct are not opposed in the way Slingerland's picture suggests (Masson 2014, 217-249). Without seriously investigating these different religious and theological ways of understanding, it is premature to conclude, that all talk of God, spirit, or soul entails that particular notion of God as a "causal agent" that many theologians today also reject. It is also premature to assume that talk of God or the spiritual entails a commitment to a dualism that conflicts with the findings of evolution and empirical science. Moreover, given these examples in the Christian tradition, it is reasonable to expect that alternative tectonic ways of understanding are revealed in other religious traditions.

Finally, the picture of tectonic blending highlights the constitutive role of the blends themselves and their inputs in the emergence of new ways of understanding, making inferences, and interacting with the world. Humans are different from other animals not only because of the emergence of the cognitive abilities that come with the capacity for double-scope blending. Humans also are different because of the ongoing emergence thorough tectonic blends of different ways of engaging with reality, such as the development of modern science, which Slingerland himself admits was brought about by the ratcheted innovation of specific conceptual blends. I am not contesting those developments in science and I agree, to use Dreyfus and Taylor's wording, that "some accounts of nature provide a better explanation of how the universe works than do others, and that our natural science provides by far the best explanation available" for understanding those questions $(2015,142)$. Bringing into focus how religious and theological blends call for decidedly new and alternate ways of understanding, making inferences, and interacting with the 
world, however, suggests, at the very least, the need to take these religious prompts seriously and the need to carefully examine them on their own terms with methods appropriate to their tectonic character. Hence we need a multi-disciplinary investigation of the evolution of religion that includes rigorous study of the specific conceptual blends of religions themselves to discover the "multiple ways of interrogating reality" that, like the natural sciences, "reveal truths independent of us...that require us to revise and adjust our thinking to grasp them..." (Dreyfus and Taylor, 154) and that call for other ways of engaging and being engaged by reality. A scientifically responsible investigation of the evolution of religion requires that this sort of attention to conceptual blending in the religions be part of the research agenda.

\section{References}

Buckley, Michael J. 1987. At the Origins of Modern Atheism. New Haven: Yale University Press.

Buckley, Michael J. 2004. Denying and disclosing God: The Ambiguous Progress of Modern Atheism. New Haven: Yale University Press.

Burrell, David B. 1979. Aquinas: God and Action. Notre Dame: Notre Dame University Press.

Dreyfus, Hubert L., and Charles Taylor. 2015. Retrieving Realism. Cambridge: Harvard University Press. Fauconnier, Gilles, and Mark Turner. 2002. The Way We Think: Conceptual Blending and the Mind's Hidden Complexities. New York: Basic Books. . 2008. "Rethinking Metaphor." In The Cambridge Handbook of Metaphor and Thought, edited by R. W. Gibbs. New York: Cambridge University Press.

Gerhart, Mary, and Allan Russell. 2001. New Maps for Old: Explorations in Science and Religion. New York: Continuum.

Lakoff, George A. 1987. Women, Fire, and Dangerous Things: What Categories Reveal about the Mind. Chicago: Chicago University Press.

Lakoff, George, and Mark Johnson. 1980. Metaphors We Live By. Chicago: Chicago University Press. 1999. Philosophy in the Flesh: The Embodied Mind and Its Challenge to Western Thought.

New York: Basic Books.

Masson, Robert. 2014. Without Metaphor, No Saving God: Theology After Cognitive Linguistics. Leuven: Peeters Press.

McCabe, Herbert. 1987. “Creation.” In God Matters. London: G. Chapman.

Sanders, John. 2016. Theology in the Flesh: How Embodiment and Culture Shape the Way We Think About Truth, Morality, and God. Minneapolis: Fortress Press.

Slingerland, Edward G. 2008. What Science Offers the Humanities: Integrating Body and Culture. New York: Cambridge University Press. 